\title{
Correction to: Research on Adaptive Updating Method of Education Resource Index Based on Mobile Computing
}

\author{
Jian-Wei Liu ${ }^{1}$ - Arun Kumar Sangaiah ${ }^{2,3}$
}

Accepted: 5 October 2021 / Published online: 5 November 2021

(c) Springer Science+Business Media, LLC, part of Springer Nature 2021

\section{Correction to: Mobile Networks and Applications (2021) https://doi.org/10.1007/s11036-021-01771-z}

The original version of this article, published on 5 May 2021, the authors have found an error in the published version of the paper. Typesetter inadvertently added the section heading "2 Conclusion" between "1 Introduction" and "3 Characteristic analysis of educational resource index" sections in the attached published version. This should be deleted.

Original article has been corrected.

Publisher's Note Springer Nature remains neutral with regard to jurisdictional claims in published maps and institutional affiliations.

The original article can be found online at https://doi.org/10.1007/ s11036-021-01771-z.

Arun Kumar Sangaiah

arunkumarsangaiah@gmail.com

Jian-Wei Liu

ljw752002@czc.edu.cn

1 Department of Electronic Information and Physics, Changzhi University, Changzhi 046011, China

2 School of Computing Science and Engineering, Vellore Institute of Technology, Vellore, India

3 Department of Industrial Engineering and Management, National Yunlin University of Science and Technology, Yunlin, Taiwan 